\title{
АГРОХИМИЧЕСКИЕ СВОЙСТВА И БИОЛОГИЧЕСКАЯ АКТИВНОСТЬ АГРОЗЁМОВ ЮЖНОЙ ТАЙГИ*
}

При вовлечении почв в сельскохозяйственное производство нарушаются природные почвообразовательные процессы. Происходит трансформация генетических горизонтов, изменение физических, химических, физико-химических и биологических характеристик почвы; в целом происходит снижение экологической устойчивости агроценозов.

Основные экологические функции почв замыкаются на одном обобщающем показателе - почвенном плодородии. Отчуждая с полей основной и побочный урожай, человек размыкает биологический круговорот веществ, нарушает способность почвы к саморегуляции и снижает ее плодородие. Даже частичная потеря гумуса и, как следствие, снижение плодородия не дает почве возможность выполнять в полной мере свои экологические функции. Причина неустойчивого состояния агроэкосистем обусловлена их упрощенным фитоценозом, который не обеспечивает оптимальную саморегуляцию, постоянство структуры и продуктивности. У природных экосистем биологическая продуктивность обеспечивается действием естественных законов природы, в агроэкосистемах выход первичной продукции (урожая) всецело зависит от человеческого фактора, уровня его агрономических знаний, технической оснащенности, социально-экономических условий и остается непостоянным. Выход почвы из обработки и переход ее в залежь со сменой растительного покрова также приводит к существенным изменениям основных свойств почв.

Для более полной характеристики состояния почв и глубокого понимания изменений почвенного плодородия, особенно при их сельскохозяйственном освоении необходимо использовать в комплексе методы по определению агрохимических и биологических свойств почвы, что позволит прийти к направленному регулированию микробиологических про-

\footnotetext{
* Исследования выполнены при финансовой поддержке РФФИ в рамках научного проекта № 18-35-00454
} 
цессов, от которых зависит плодородие почв и урожайность сельскохозяйственных культур. Таким образом, цель данной работы - изучить агрохимические свойства и биологическую активность агрозёмов южной тайги.

Для изучения агрохимической и ферментативной активности агрозёмов южной тайги в северной окраинной части Амуро-Зейской равнины (с. Гулик) выбраны три биогеоценоза: сенокос, залежь и лес, в которых было заложено три учетных площади (УП) каждая по $50 \mathrm{~m}^{2}$. Первая УП представляет собой ненарушенный ценоз - лес (Л) (53²43'49,7"; 12704'01,1"),

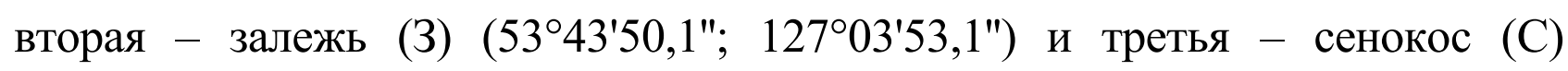

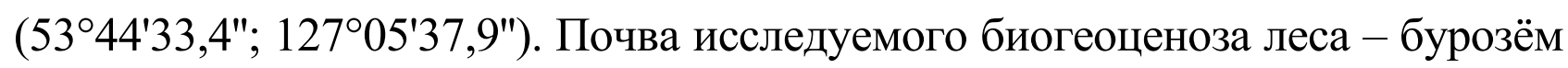
оподзоленный, залежи - бурозём глееватый, сенокоса - бурозём-глеевый.

Для определения основных агрохимических и биологических свойств исследуемых почв с каждой учетной площади отобрано по 5 почвенных образцов с помощью металлического цилиндра диаметром 5 см с глубины 0-20 см. Общее количество почвенных образцов с трёх учетных площадок (лес, залежь, сенокос) - 15 штук. Почвенные образцы высушивали до воздушно сухого состояния, измельчали и пропускали через сито с диаметром ячеек 2 мм. При изучении физико-химических показателей почв определяли потенциальную кислотность по ГОСТ 26483-90, сумму обменных оснований комплексонометрическим методом по ГОСТ 26487-90. Определение подвижных форм фосфора $\left(\mathrm{P}_{2} \mathrm{O}_{5}\right)$ и калия $\left(\mathrm{K}_{2} \mathrm{O}\right)$ осуществляли по методу А.T. Кирсанова (ГОСТ PS4650-2011). При изучении биологических показателей определяли активность ферментов класса гидролаз: уреазы - методом А.Ш. Галстяна [Муртазина, 2006] и фосфатазы - методом гидролиза фенолфталеин фосфата [Временные методические..., 1984] и активность фермента класса оксидоредуктаз - каталазы по Джонсону и Темпле перманганатометрическим методом [Муртазина, 2006].

Результаты лабораторных определений и фактические данные полевых измерений обработаны методами математической статистики в программе R версия 3.3.2 (R Core Team). Статистические различия между исследуемыми биогеоценозами устанавливали при помощи однофакторного дисперсионного анализа (ANOVA). Для принятия различий руководствовались уровнем статистической значимости - вероятностью отклонения нулевой гипотезы, в то время как она верна. При этом, когда указываем, что различия достоверны на $5 \%$ уровне значимости, или при $\mathrm{p} \leq 0,05$, то 
имеем ввиду, что вероятность того, что они недостоверны, составляет 0,05. В работе принимаются традиционные 0,05 за критический уровень значимости и вероятность ошибки 1 типа составляет 5\%, значит, вероятность отсутствия этой ошибки составит 0,95 (или 95\%).

Исследования агрозёмов южной тайги дают возможность оценить ряд важных агрохимических свойств, дать комплексную характеристику плодородия почв. Агрохимические свойства определены в 2017 г. в почвах исследуемых биогеоценозов.

Среди изучаемых биогеоценозов наименьшая полевая влажность почвы в слое 0-20 см наблюдалась в лесу (16\%), наибольшая - на сенокосе (25\%). Влажность почвы на сенокосе была выше на 7-9 \%, чем на залежи и в лесу $(\mathrm{p}<0,001)$. Вероятно, это обусловлено значительным увеличением количества осадков, поступающих на поверхность почвы и уменьшением влаги, испаряемой в результате транспирации растений (рис. 1).

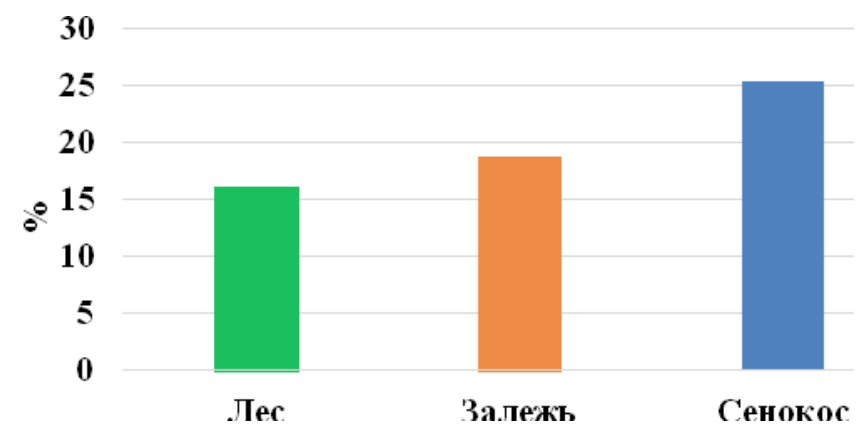

Puc. 1. Полевая влажность почв в изучаемых биогеоценозах

Почвы изучаемых биогеоценозов имеют кислую реакцию среды. В почвах леса и сенокоса обменная кислотность составила 4,2 ед. $\mathrm{pH}$, в почвах залежи - 4,7 ед. $\mathrm{pH}$.

Содержание подвижного фосфора в почвах лесного биогеоценоза повышенное, на залежи - высокое, на сенокосе - среднее. Содержание фосфора в слое почвы 0-20 см исследуемых биогеоценозов варьирует. Наименьшее содержание фосфора наблюдалось в почвах сенокоса 98 мг/кг, наибольшее - в почвах залежи 185 мг/кг (рис. 2). Содержание фосфора в почвах залежи было выше на 24-47 \%, чем в почвах леса и сенокоса. Сельскохозяйственное использование земель привело к снижению содержание подвижного фосфора в почве сенокоса. 

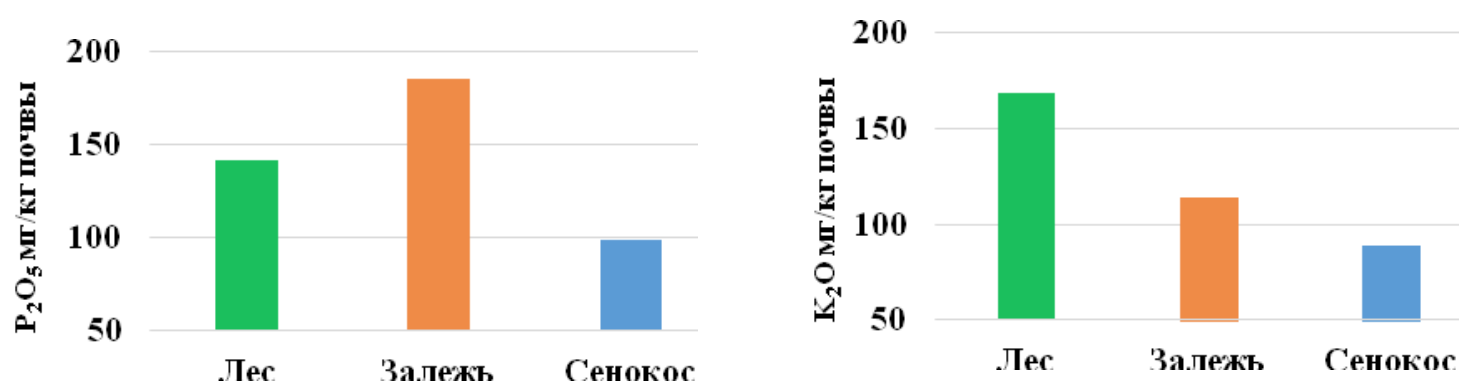

Puc. 2. Содержание подвижного фосфора и калия в почвах исследуемых биогеоценозов

Содержание подвижного калия в почвах лесного биогеоценоза повышенное, на залежи и сенокосе - среднее (рис. 2). Наименьшее содержание калия наблюдалось в почвах сенокоса - 89 мг/кг, наибольшее - в почвах леса 169 мг/кг. Таким образом, содержание калия в почвах леса было выше на 32-47 \%, чем в почвах залежи и сенокоса $(\mathrm{p}<0,001)$. Сельскохозяйственное использование земель привело к снижению содержание подвижного калия в почве сенокоса. На фоне исследуемых биогеоценозов большое содержания калия в почвах целины вероятно связано с пожарами, последствием которых становится образование золы, что способствует накоплению калия в верхних горизонтах почвы.

Сумма поглощенных оснований в агрозёмах южной тайги во всех изучаемых биогеоценозов низкая и в составе поглощенных катионов преобладает ион кальция (рис. 3). Кальций входит в состав обменнопоглощенных катионов и имеет огромное значение, как в питании растений, так и в почвообразовании. В почвах леса в слое 0-20 см кальция содержится 5,2 мг-экв/100 г почвы, на залежи и сенокосе - 7,8 и 8,2 мг-экв $/ 100$ г почвы. Таким образом, содержание кальция в почвах залежи и сенокоса было выше на 50-60 \%, чем в почвах леса $(\mathrm{p}<0,001)$. Содержание магния в почвах исследуемых биогеоценозов достоверно не различается.

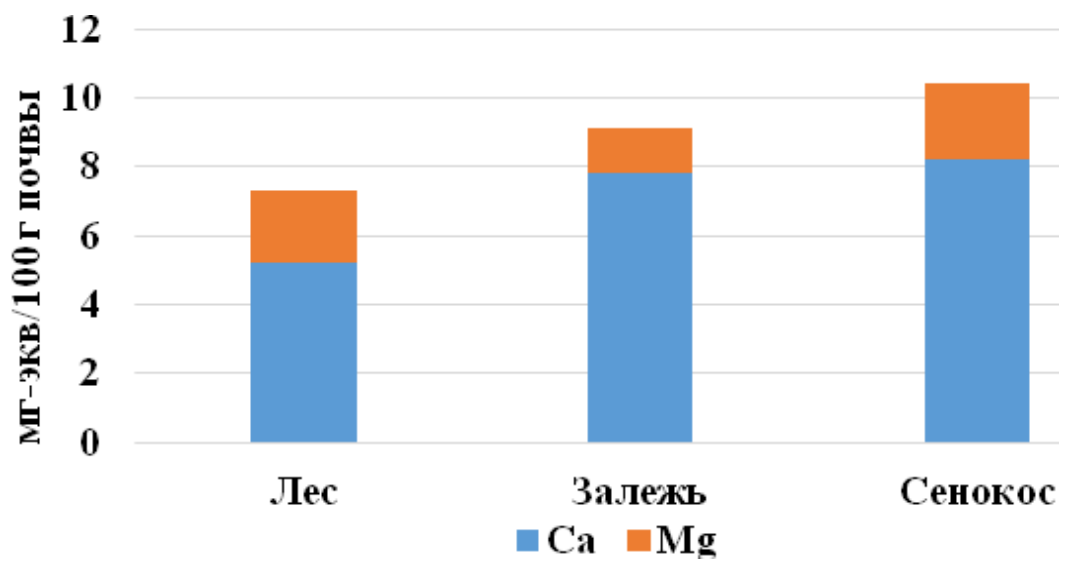

Рис. 3. Содержание обменных оснований в почвах исследуемых биогеоценозов 
Наиболее чувствительными индикаторами деградации почв при различных антропогенных воздействиях являются показатели биологической активности почвы [Козунь, 2015]. Все биологические процессы, связанные с превращением веществ и энергии в почве, осуществляются с помощью ферментов, играющих важную роль в мобилизации элементов питания растений. Относительный уровень ферментативной активности почв диагностирует интенсивность и направленность почвообразовательных процессов в естественных условиях и при различных антропогенных воздействиях на почву. Важная роль ферментов заключается в том, что они осуществляют функциональные связи между компонентами экосистемы, поэтому ферментативная активность отражает функциональное состояние почвенного населения [Yang Lijuan, 200].

При изучении фосфатазной активности исследуемых биогеоценозов наибольшая активность фермента выявлена на залежи - 28,5 мг, наименьшая на сенокосе - 19,3 мг (рис. 4). Активность фосфатазы в почвах залежи выше на 25-32 \%, чем в почвах леса и сенокоса $(\mathrm{p}<0,001)$. Согласно шкалы сравнительной оценки биохимической активности почвы фосфатазная активность исследуемых агрозёмов очень высокая [Казеев К.Ш., 2003].

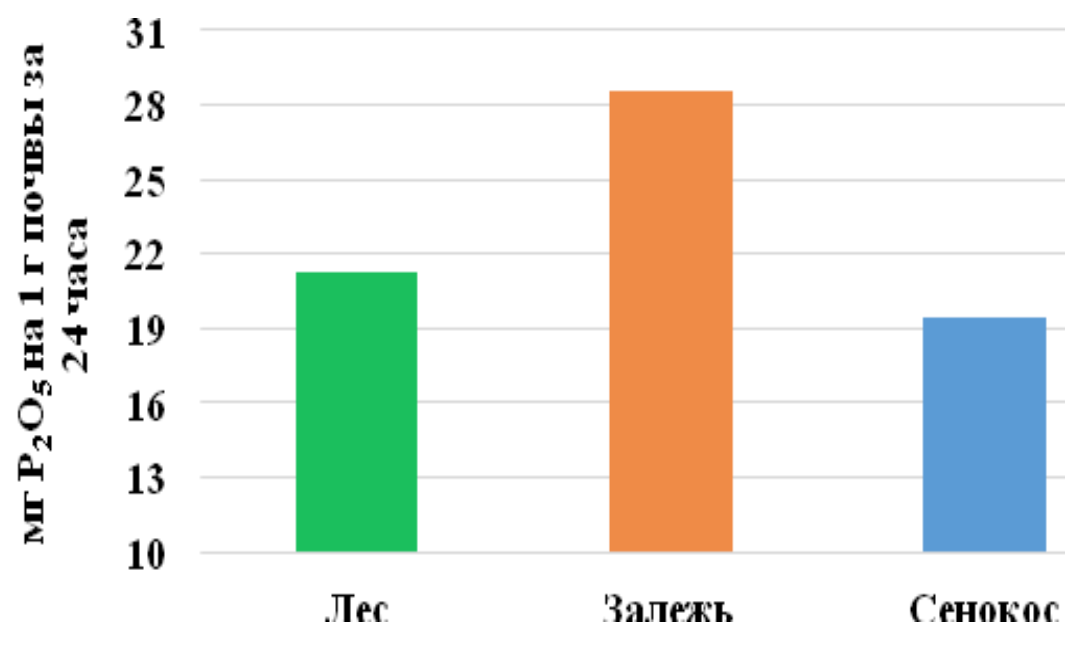

Рис. 4. Активность фосфатазы в почвах исследуемых биогеоценозов

Активность фосфатазы находится в обратной зависимости от обеспеченности растений подвижным фосфором. Данная закономерность может быть обусловлена реакцией живых организмов на содержание доступных форм фосфора в окружающей среде и экономией ресурсов по выработке фосфатазы. Для установления зависимости активности фосфа- 
тазы от содержания подвижного фосфора в почвах исследуемых биогеоценозов выполнен линейный корреляционный анализ (табл. 1). Выборка была составлена по средним значениям показателей исследуемых биогеоценозов, $\mathrm{n}=5$, при $\mathrm{r}_{\text {крит }}=0,878$.

Таблица 1

Корреляционная связь активности фосфатазы с содержанием подвижного фосфора в почвах исследуемых биогеоценозов $\left(\mathbf{n}=5, \mathbf{r}_{\text {крит }}=0,878\right)$

\begin{tabular}{|c|c|c|c|}
\hline \multirow{2}{*}{ Показатель } & \multicolumn{3}{|c|}{ Содержание подвижного фосфора } \\
\cline { 2 - 4 } & Лес & Залежь & Сенокос \\
\hline $\begin{array}{c}\text { Активность } \\
\text { фосфатазы }\end{array}$ & 0,573 & $-0,307$ & $-0,462$ \\
\hline
\end{tabular}

Обратная корреляционнаная зависимость между содержанием подвижного фосфора и активностью фосфатазы прослеживается только в почвах залежи и сенокоса, при этом корреляционная зависимость средняя (r от 0,3 до 0,7), но статистически недостоверная при данной величине выборки (табл.1). В почвах леса зависимость между содержанием подвижного фосфора и активностью фосфатазы средняя прямая $(\mathrm{r}=0,573)$ и также статистически недостоверная при данной величине выборки. В агроэкосистемах осуществляется круговорот веществ, сопровождающийся потерями элементов, поэтому закономерность обратной корреляции в наших исследованиях подтверждается, так как именно в почвах сенокоса, снижается содержание подвижного фосфора при этом активность фосфатазы остаётся на очень высоком уровне.

При изучении уреазной активности исследуемых биогеоценозов наибольшая активность фермента выявлена на залежи - 0,3 мг, наименьшая на сенокосе - 0,01 мг (рис. 5).

Активность уреазы в почвах залежи выше на 3-20\%, чем в почвах сенокоса и леса $(\mathrm{p}<0,001)$. Согласно шкале сравнительной оценки биохимической активности почвы уреазная активность исследуемых почв очень слабая [Казеев К.Ш., 2003].

При изучении каталазной активности исследуемых биогеоценозов наибольшая активность фермента выявлена в почвах леса и сенокоса $0,38 \mathrm{~cm}^{3}$ и $0,37 \mathrm{~cm}^{3}$. Низкий показатель активности фермента каталаза сре- 
ди изучаемых биогеоценозов имеет почва залежи - 0,33 $\mathrm{cm}^{3}$ (рис. 6). Таким образом, активность каталазы в почвах леса была недостоверно выше на 1-9 \%, чем в почвах сенокоса и залежи. Большое влияние на каталазную активность почв оказывает растительность. Как правило, почвы, находящиеся под растениями с глубоко проникающей корневой системой, характеризуются высокой каталазной активностью. Согласно шкалы сравнительной оценки биохимической активности почвы каталазная активность исследуемых почв очень слабая [Казеев К.Ш., 2003].

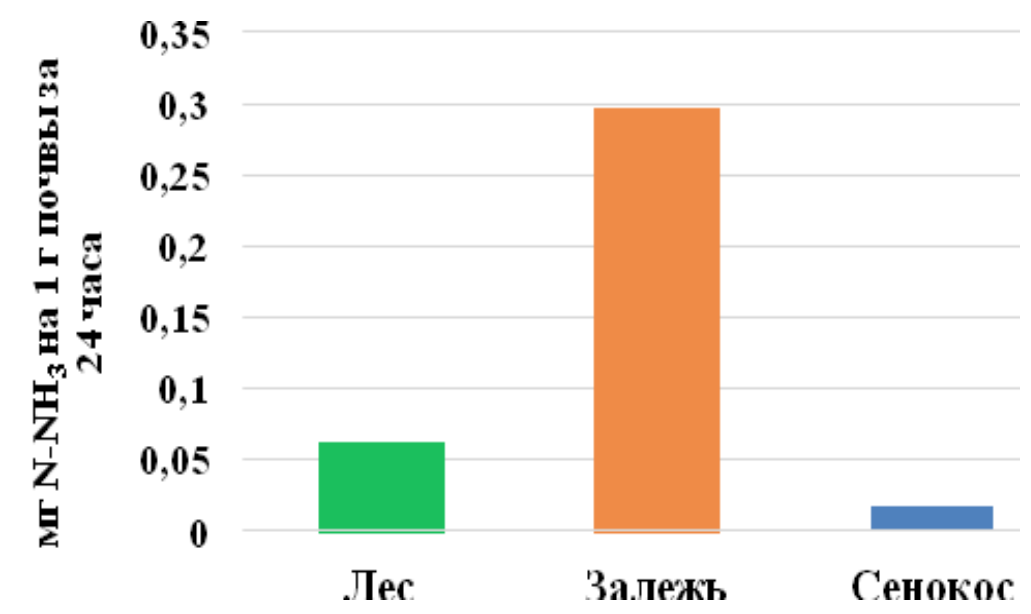

Рис. 5. Активность уреазы в почвах исследуемых биогеоценозов

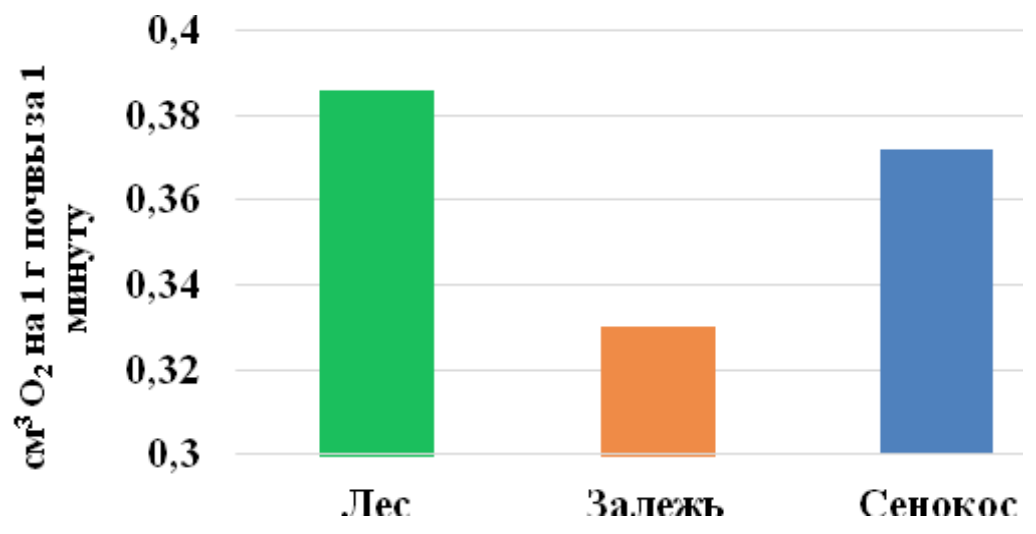

Puc. 6. Активность каталазы в почвах исследуемых биогеоценозов

Распашка и освоение лесных земель агрозёмов южной тайги северной окраиной части Амуро-Зейской равнины привело к достоверному увеличению влажности. В результате агрохимических исследований установлено, что почвы исследуемых биогеоценозов кислые. Содержание подвижного фосфора в почвах лесного биогеоценоза повышенное, на залежи - высокое, на сенокосе - среднее. Содержание подвижного калия в почвах лесного 
биогеоценоза повышенное, на залежи и сенокосе - среднее. Сумма поглощенных оснований в агрозёмах южной тайги во всех изучаемых биогеоценозах низкая и в составе поглощенных катионов преобладает ион кальция.

При изучении ферментативной активности агрозёмов южной тайги установлено, что активность фосфатазы очень высокая, уреазы и каталазы низкая. Активность фосфатазы и уреазы достоверно увеличилась в почвах залежи, уменьшилась - в почвах сенокоса. Активность каталазы в почвах изучаемых биогеоценозах достоверно не изменялась. Таким образом, распашка и освоение целинных земель агрозёмов южной тайги привели к достоверному снижению содержания подвижного фосфора, калия, активности уреазы и фосфатазы в почве сенокоса.

\section{Литература}

1. Временные методические рекомендации по контролю загрязнения почв / С.Г. Малахов. - Москва: Московское отделение гидрометеоиздата, 1984.

2. Казеев К.Ш. Биологическая диагностика и индикация почв: методология и методы исследований / К.Ш. Казеев, С.И. Колесников, В.Ф. Вальков. - Ростов-на-Дону: Изд-во РГУ, 2003. - 216 С.

3. Козунь, Ю.С. Изменение биологической активности бурой лесной почвы при сельскохозяйственном использовании [Текст] / Ю.С. Козунь, К.Ш. Казеев, С.И. Колесников, Ю.В. Акименко, М.А. Мясникова // Политематический сетевой электронный научный журнал Кубанского государственного аграрного университета. - 2015. - №112. - С. 718 - 728.

4. Муртазина, С.Г. Практикум по почвоведению / С.Г. Муртазина, И.А. Гайсин, М.Г. Муртазин. - Казанская государственная сельскохозяйственная академия, 2006. - 225 с.

5. Yang, Lijuan. Fertilization regulates soil enzymatic activity and fertility dy-namics in a cucumber field / Lijuan Yang, Tianlai Li, Fusheng Li et al. // Scientia Horticul-turae. - 2008. - Vol. 116, № 1. - P. 21-26. 